\title{
ENGINEERED SPLIT-TET2 ENZYME FOR INDUCIBLE EPIGENETIC REMODELING
}

\author{
A Thesis \\ by \\ YI LIANG \\ Submitted to the Office of Graduate and Professional Studies of \\ Texas A\&M University \\ in partial fulfillment of the requirements for the degree of \\ MASTER OF SCIENCE
}

$\begin{array}{ll}\text { Chair of Committee, } & \text { Yubin Zhou } \\ \text { Committee Members, } & \text { Fen Wang } \\ & \text { Dekai Zhang } \\ & \text { Michael Zhu } \\ \text { Head of Program, } & \text { Warren Zimmer }\end{array}$

December 2017

Major Subject: Medical Sciences

Copyright 2017 Yi Liang 


\begin{abstract}
The conversion of 5-methylcytosine $(5 \mathrm{mC})$ into 5-hydroxymethylcytosine $(5 \mathrm{hmC})$ and further oxidized species is catalyzed by the Ten-eleven translocation (TET) methylcytosine dioxygenase. Here we provided a temporal control of $5 \mathrm{mC}$ oxidation and subsequent remodeling of epigenetic states through a split-TET2 enzyme system in mammalian cells. This chemical-inducible epigenome remodeling tool provides a precise way to interrogate cellular systems and probe the epigenotype-phenotype relations in various biological systems.
\end{abstract}




\section{ACKNOWLEDGEMENTS}

I would like to thank my committee chair, Dr. Yubin Zhou, and my committee members, Dr. Fen Wang, Dr. Dekai Zhang, Dr. Michael Zhu, for their guidance and support throughout the course of this research.

Thanks also go to my friends and colleagues and the department faculty and staff for making my time at Texas A\&M University a great experience.

Finally, thanks to my mother and father for their encouragement and to my wife for her patience and love. 


\section{CONTRIBUTORS AND FUNDING SOURCES}

\section{Contributors}

This work was supervised by a thesis (or) dissertation committee consisting of Professor Yubin Zhou of the Department of Center for Translational Cancer Research -IBT.

The part of the data in Section 2 was conducted by Minjung Lee from Dr. Yun Huang's Lab -- IBT.

All other work conducted for the thesis was completed by the student independently.

\section{Funding Sources}

This work was made possible in part by National Institutes of Health grant (R01GM112003), the Welch Foundation (BE-1913), the American Cancer Society (RSG16-215-01 TBE), the Cancer Prevention and Research Institute of Texas (RR140053, RP120348 and RP170002) and by an allocation from the Texas A\&M University Health Science Center Startup Fund. 


\section{NOMENCLATURE}

$\begin{array}{ll}\text { TAMU } & \text { Texas A\&M University } \\ \text { IBT } & \text { Institute of Biosciences \& Technology } \\ \text { CTCR } & \text { Center for Translational Cancer Research } \\ \text { TET } & \text { Ten-eleven translocation dioxygenases } \\ \text { 5mC } & \text { 5-methylcytosine } \\ \text { 5hmC } & \text { 5-hydroxymethylcytosine } \\ \text { DNMTs } & \text { DNA methyltransferases } \\ \text { 5fC } & \text { 5-formylmethylcytosine } \\ \text { 5caC } & \text { 5-carboxymethylcytosine } \\ \text { TET2CD } & \text { Catalytic domain of human TET2 } \\ \text { DSBH } & \text { Double stranded beta-helix } \\ \text { FKBP12 } & \text { FK506 binding protein 12 } \\ \text { FRB } & \text { FKBP rapamycin binding domain } \\ \text { HEK293T } & \text { Chemical-inducible epigenome remodeling tool } \\ \text { Cas9 } & \text { CRER associated protein 9 } \\ & \end{array}$




\section{TABLE OF CONTENTS}

Page

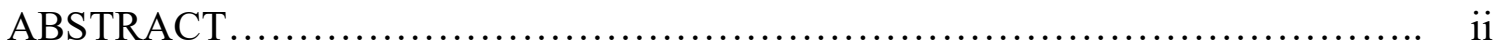

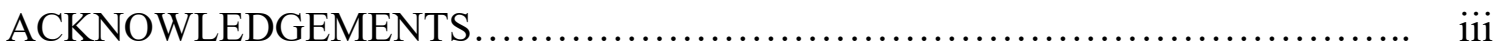

CONTRIBUTORS AND FUNDING SOURCES $\ldots \ldots \ldots \ldots \ldots \ldots \ldots \ldots \ldots \ldots \ldots \ldots$ iv

NOMENCLATURE....................................................... v

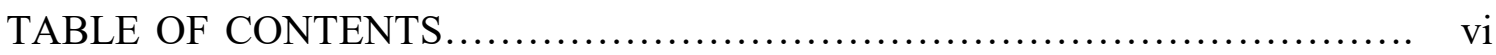

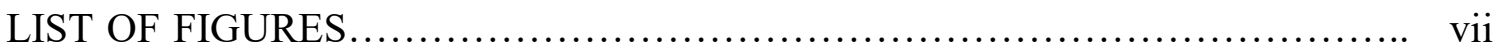

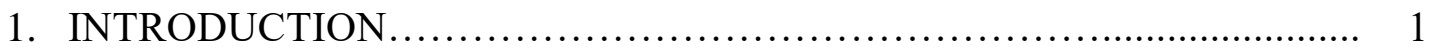

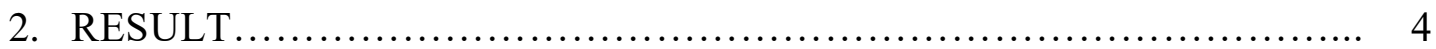

2.1 Design and optimization of Split-TET2CD constructs................. 4

$2.25 \mathrm{hmC}$ level is increased by CiDER upon rapamycin induction in mammalian cells............................................. 6

2.3 Reversibility of CiDER triggered $5 \mathrm{hmC}$ raise....................... 9

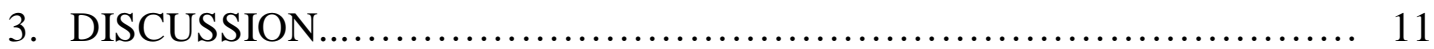

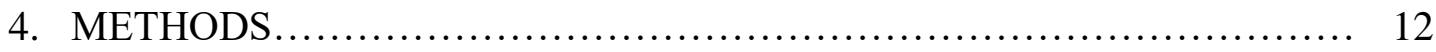

4.1 Cell culture and plasmid transfection .............................. 12

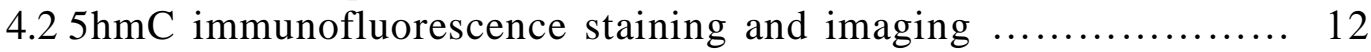

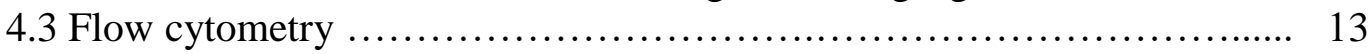

4.4 A dot-blot assay to quantify genomic $5 \mathrm{hmC}$ and $5 \mathrm{mC} \ldots \ldots \ldots \ldots . . . \ldots 13$

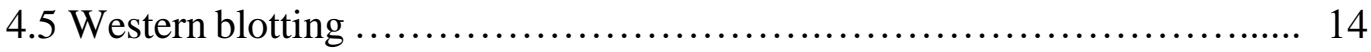

4.6 Pull-down experiments and functional reconstitution in vitro........... 15

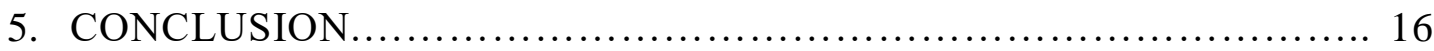

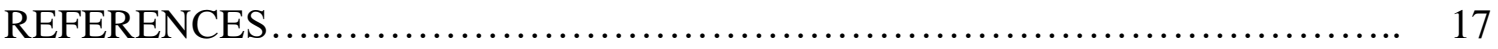

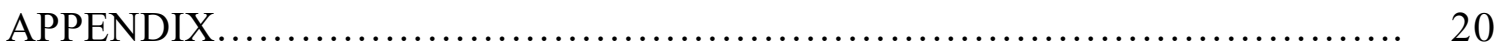




\section{LIST OF FIGURES}

Page

Figure 1. An engineered split-TET2 enzyme for inducible DNA hydroxymethylation in mammalian cells .................................. 5

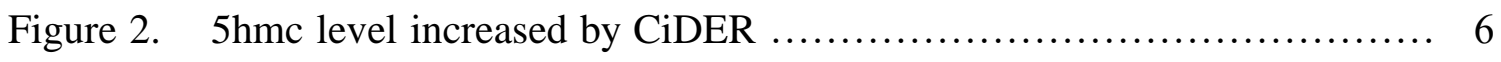

Figure 3. Time course of rapamycin-induced production of $5 \mathrm{hmC} \ldots \ldots \ldots \ldots \ldots \ldots$ 


\section{INTRODUCTION}

DNA methylation, catalyzed by DNA methyltransferases (DNMTs), is a process in which a methyl group is added to the carbon 5 position of cytosine to form $5 \mathrm{mC}$. $5 \mathrm{mC}$ has been considered as an epigenetic mark that functions in transcriptional repression, $\mathrm{X}$ chromosome inactivation and transposon silencing in the mammalian genome ${ }^{1}$. The recovery of $5 \mathrm{mC}$ to cytosine is a successive process in which Tet-eleven translocation (TET) family of methylcytosine dioxygenases catalyze the oxidation of $5 \mathrm{mC}$ to 5 hydroxymethylcytosine $\quad(5 \mathrm{hmC}), \quad$ 5-formylmethylcytosine $\quad(5 \mathrm{fC}) \quad$ and 5 carboxymethylcytosine $(5 \mathrm{caC})^{2-4}$. This process adds an additional layer of previously underappreciated epigenetic control over the mammalian genome. $5 \mathrm{hmC}$ catalyzed by TET proteins has been considered to serve as a rate limiting process of TET-mediated DNA demethylation ${ }^{2-4}$, as well as a reliable epigenetic mark ${ }^{5-8}$. Evidence shows that DNA hydroxymethylation is highly correlated with gene expression and some function

disorders $^{9-11}$. However, it is still a challenge to establish the causal relations between epigenetic modifications on DNA and the phenotypes, owing to the lack of reliable tools to accurately control DNA methylation in genome at temporal and spatial resolution.

To overcome this challenge, we designed a chemical-inducible epigenome remodeling tool (CiDER, Scheme 1) to acquire the precise control of adding or removing epigenetic DNA modifications to further control the transcription of genes. Rather than TET1 or TET3, the catalytic domain of human TET2 (TET2CD, Figure1) has been selected as the 


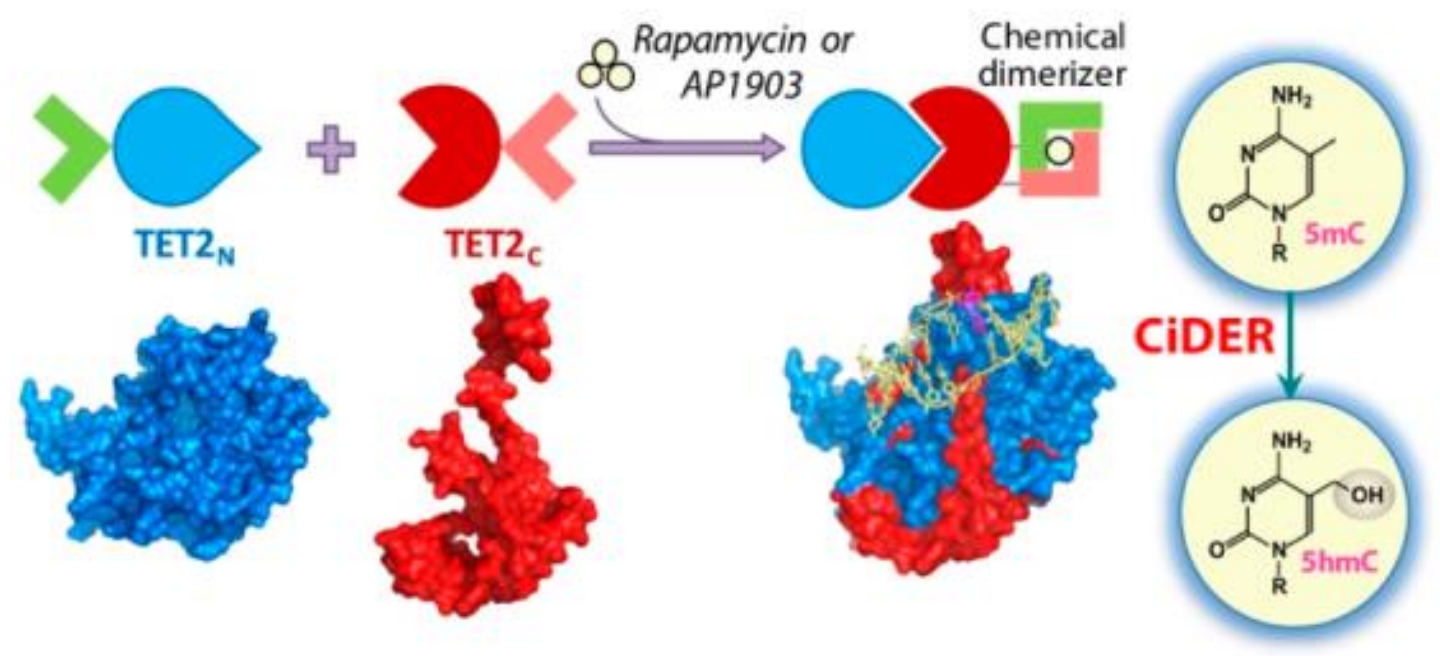

Scheme 1. Design of a chemical-inducible epigenome remodeling(CiDER) tool based on a split TET2 enzyme. FKBP12/FRB heterodimerization or FKBP-F36 V homodimerization modules are fused with two inactive fragments of a split TET2CD. Upon the addition of rapamycin, split TET2CD fragments reassemble into a functional methylcytosine dioxygenase to catalyze the conversion of $5 \mathrm{mC}$ into $5 \mathrm{hmC}$ and further oxidized species, thus promoting DNA demethylation to remodel the epigenetic landscapes in mammalian cells. Reprinted with permission from Engineered Split-TET2 Enzyme for Inducible Epigenetic Remodeling by Minjung Lee, Jia Li, Yi Liang, J. Am. Chem. Soc., 2017, 139 (13), pp 4659-4662, http://pubs.acs.org/doi/abs/10.1021\%2Fjacs.7b01459

subject for a split epigenomic modifier for the following major reasons. First, in hematological malignancies ${ }^{10}$, TET2 is the most frequently mutated gene. Plenty of exome sequencing data of cancer patients provide abundant information of sensitive spots that need to be avoided through the engineering process ${ }^{12-13}$. Second, the structure of TET2CD in complex with $5 \mathrm{mC}$ or $5 \mathrm{hmC}$ is the only one that has been determined among TET proteins $^{14-15}$, which provides more rationale to the selection of split sites. Third, there is a low complexity region (residues 1481-1843) existing in TET2CD which is possible to be replaced by a flexible GS linker without significantly compromising the catalytic activity, 
and hence it offers a structural malleability of TET2CD and increases the flexibility to accommodate the insertion of foreign polypeptide sequences ${ }^{15}$. The replacement of this large fragment of low complexity $(\sim 1.2 \mathrm{~kb})$ also helps us to minimize the size of the constructs. Then, we set out to test the idea that the two inactive fragments of split TET2CD can be restored by a chemically inducible dimerization approach. 


\section{RESULT}

\subsection{Design and optimization of Split-TET2CD constructs}

To develop a split-TET2CD system, six sites have been selected on a Cys-rich region and a double-stranded beta-helix (DSBH) fold (Figure 1a,b). A FK506 binding

protein 12 (FKBP12) and FKBP rapamycin binding domain(FRB) ${ }^{16-17}$ separated by a selfcleaving T2A polypeptide sequence ${ }^{18-19}$ was inserted between the selected split sites of TET2CD or TET2CD with a GS linker instead of the low complexity region. A mCherrytag was added on the C-terminal of the constructs (Figure 1c). 

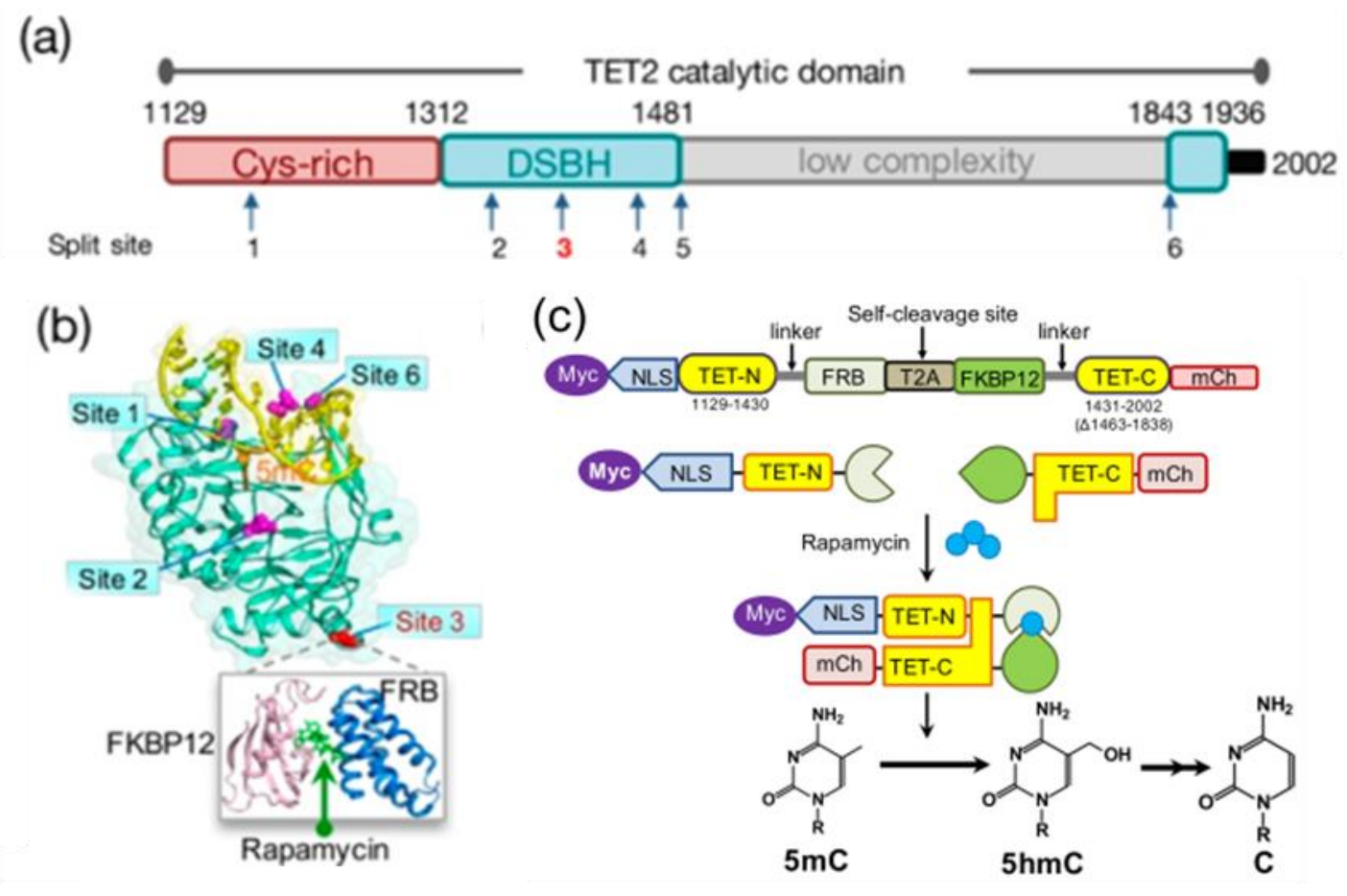

Figure 1. An engineered split-TET2 enzyme for inducible DNA hydroxymethylation in mammalian cells. (a) Domain architecture of the catalytic domain of TET2 (TET2CD; aa 1129-2002) and positions of selected split sites. DSBH, double stranded beta helix. (b) Split sites mapped to the 3D structure of TET2CD (PDB entry: 4NM6) (c) Diagram of CiDER. The chemical-inducible dimerization modules FRB and FKBP12, along with a self-cleaving peptide T2A, was inserted into the catalytic domain of TET2 (TET2CD with deletion of residues 1462-1839) at split site 3 (Figure 1). The N-terminal region of TET2CD (TETN) is tagged with an Myc tag and a nuclear localization signal (NLS); whereas the C-terminal region of TET2CD (TET-C) is fused with mCherry to aid the detection of protein expression. Following the expression of CiDER in mammalian cells, the fusion protein will be cleaved into two inactive TET2CD fragments. Upon addition of rapamycin, the chemically-inducible heterodimerization of FRB and FKBP12 brings the two complementary fragments of TET2CD into close proximity to restore its enzymatic function, thereby catalyzing $5 \mathrm{mC}$ oxidation to produce 5hmC. Reprinted with permission from Engineered Split-TET2 Enzyme for Inducible Epigenetic Remodeling by Minjung Lee, Jia Li, Yi Liang, J. Am. Chem. Soc., 2017, 139 (13), pp 4659-4662, http://pubs.acs.org/doi/abs/10.1021\%2Fjacs.7b01459 


\section{2 $5 \mathrm{hmC}$ level is increased by CiDER upon rapamycin induction in mammalian}

cells

Each construct was transfected into human embryonic kidney 293T (HEK293T)

or Hela cells that both have extremely low basal $5 \mathrm{hmC}$ levels. The fusion protein was self-

cleaved into two fragments once transfected into HEK293T cells (Figure 2a).

Figure 2. 5hmc level increased by CiDER. (a) Western blotting to detect the expression of two split TET2CD

fragments. The N-terminal domain was detected by the anti-Myc antibody (left; calculated MW = 51.9 kDa)

whereas the Chalf was immunoblotted against an anti-mCherry monoclonal antibody (right; calculated MW $=64.1$

$\mathrm{kDa}$ ). (b) Screening and optimization of split-TET2CD constructs to achieve chemical-inducible 5hmC generation in HEK293T cells. The construct with insertion of FKBP12-T2A-FRB at split site 3 and deletion of the low complexity region ( $\triangle 1462-1839)$ stood out as the best candidate (termed "CiDER", S1). (c) Quantification of CiDER-mediated $5 \mathrm{hmC}$ production by flow cytometry. HEK293T cells transfected with mCherry (mCh)-tagged

CiDER or mCh-TET2CD (positive control) were mmunostained with an anti-5hmC primary antibody and an FITC-labeled secondary antibody. (d) Dot-blot assay to quantify rapamycin (200 nM)-induced changes of $5 \mathrm{hmC}$ levels in genomic DNA purified from HEK293T cells expressing CiDER or TET2CD. A synthetic oligonucleotide with a known amount of $5 \mathrm{hmC}$ was used as a positive control. The loading control was shown in the bottom panel by methylene blue staining of total amounts of input DNA. (e) Representative fluorescent images of 5hmC (green), CiDER-mCh (red), and nuclear staining with DAPI (blue) in HEK293T cells before and after rapamycin (200 nM) treatment. Reprinted with permission from Engineered Split-TET2 Enzyme for Inducible Epigenetic Remodeling by Minjung Lee, Jia Li, Yi Liang, J. Am. Chem. Soc., 2017, 139 (13), pp 4659-4662,

http://pubs.acs.org/doi/abs/10.1021\%2Fjacs.7b01459 
(a)

TET2CD CIDER

TET2CD CiDER

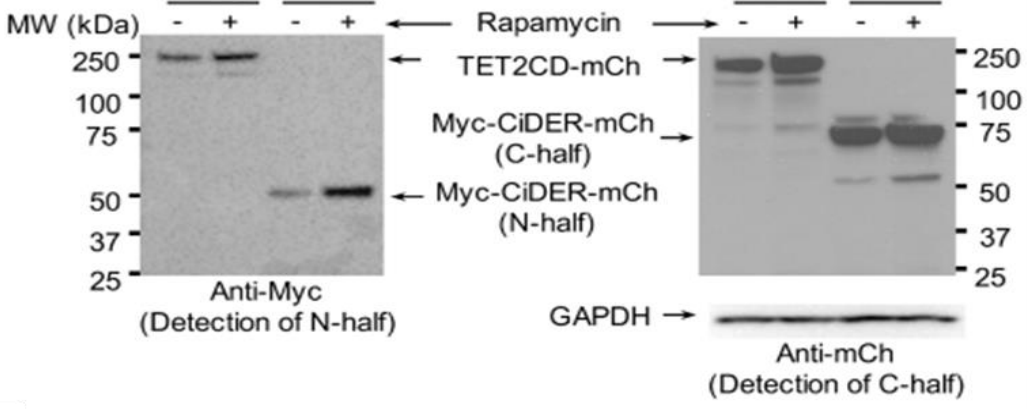

(b)

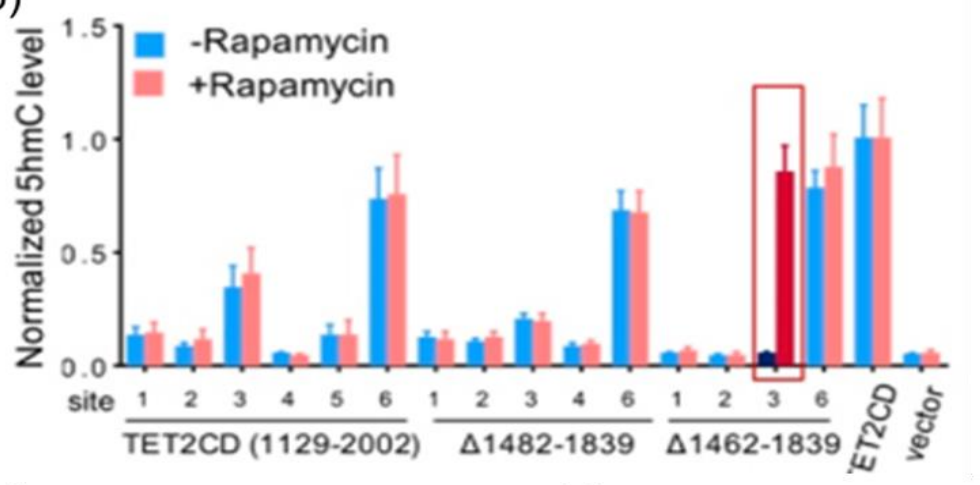

(c)

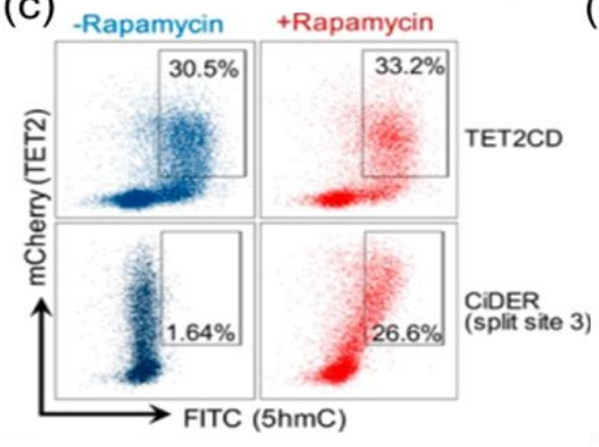

(d)
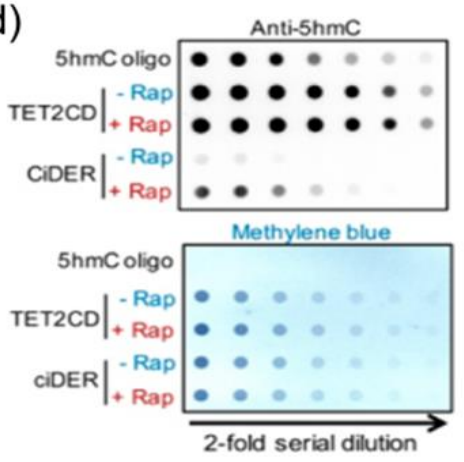

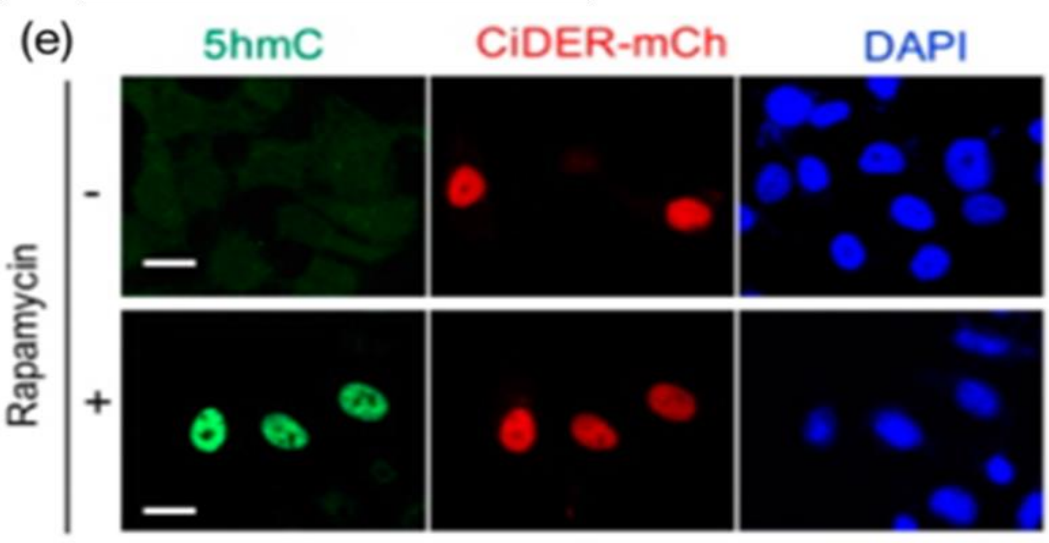


In the presence of rapamycin, the production of $5 \mathrm{hmC}$ was increased after incubating the enriched fragments with a synthetic 5mC-containing dsDNA oligo in vitro, indicating that the two fragments could reconstitute a functional enzyme. We further compared global $5 \mathrm{hmC}$ levels before and after rapamycin treatment by flow cytometry (Figure 2b,c). We identified a split-TET2CD variant (designated as CiDER for chemicalinducible epigenome remodeling tool) that shows the restoration of enzymatic activity through rapamycin induction after screening over 15 constructs. There was almost no background activity of CiDER prior to the addition of rapamycin. The total $5 \mathrm{hmC}$ level was restored in the cells that expressed intact integrated TET2CD proteins after rapamycin induction (Figure $2 \mathrm{~b}, \mathrm{c}$ ). We further confirmed the generation of $5 \mathrm{hmC}$ by rapamycin 
induction through two additional methods: immunostaining and a more quantitative dotblot assay that measures the total amounts of $5 \mathrm{hmC}$ in the whole cell population. It was confirmed by both methods that rapamycin elicited robust production of $5 \mathrm{hmC}$ in CiDERexpressing HEK293T cells (Figure 2d,e).

\subsection{Reversibility of CiDER triggered 5hmC raise}

To detect the reversibility of CiDER, we monitored rapamycin-induced 5hmC level at different time points. The result showed that $5 \mathrm{hmC}$ level reached a maximum in about 48 hours with rapamycin treatment. The $5 \mathrm{hmC}$ level returned to its basal level in about 3 days after the withdrawal of rapamycin, indicating the constant dilution of $5 \mathrm{hmC}$ level after multiple rounds of cell division. By contrast, the $5 \mathrm{hmC}$ level in the group with intact TET2CD remained at high level regardless of whether rapamycin was added or removed. (Figure 3). 


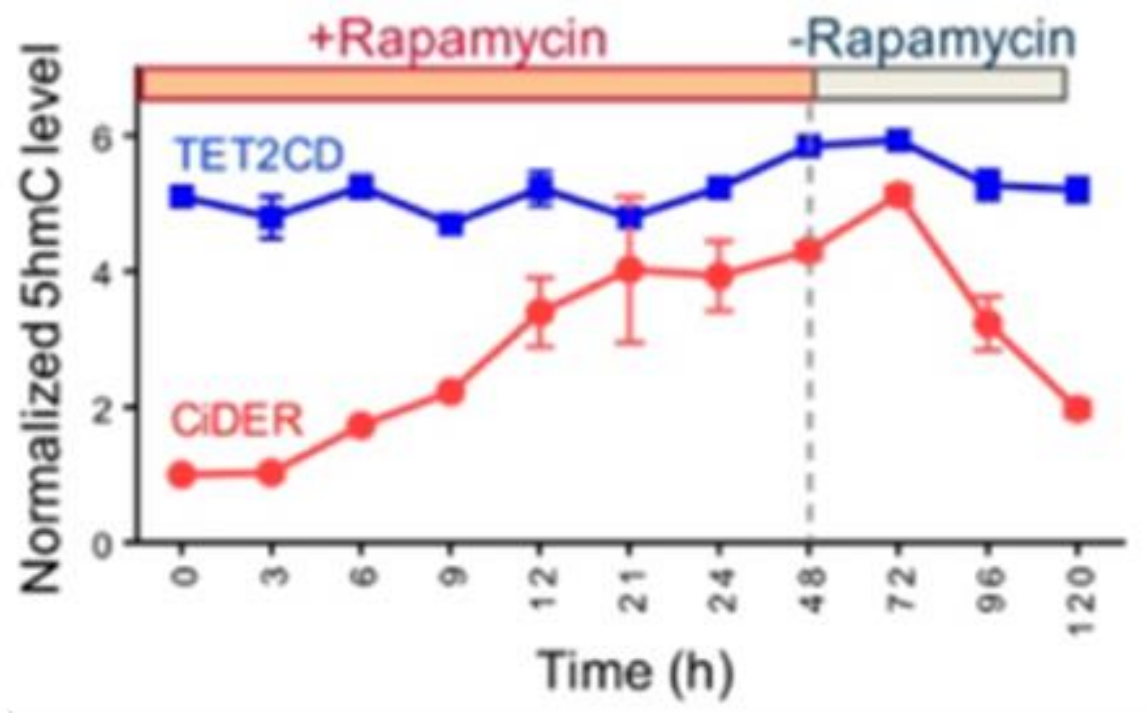

Figure 3. Time course of rapamycin (200 nM)-induced production of 5hmC in HEK293T cells expressing CiDER or TET2CD (as positive control). Rapamycin was washed away $48 \mathrm{~h}$ after incubation with cells. Reprinted with permission from Engineered Split-TET2 Enzyme for Inducible Epigenetic Remodeling by Minjung Lee, Jia Li, Yi Liang, J. Am. Chem. Soc., 2017, 139 (13), pp 4659-4662, http://pubs.acs.org/doi/abs/10.1021\%2Fjacs.7b01459 


\section{DISCUSSION}

To further improve CiDER system to achieve the spatial control of 5hmC level, we plan to fuse it with a catalytically inactive Cas9 or its orthologues which offer the possibility of loci-specific targeting of DNA demethylation in genome. It's quite possible that the loci-specific CiDER system could become a powerful tool for interrogating, perturbing and engineering cellular system without altering the genetic code. as well as reprogramming cell fate and disease intervention. 


\section{METHODS}

\subsection{Cell culture and plasmid transfection}

HeLa and human embryonic kidney HEK293T cell lines from the American Type Culture Collection (ATCC) were cultured in Dulbecco's modified Eagle's medium (DMEM, Sigma-Aldrich), supplemented with $10 \%$ heat-inactivated fetal bovine serum, $100 \mathrm{U} / \mathrm{ml}$ penicillin/ streptomycin at $37^{\circ} \mathrm{C}$ with $5 \% \mathrm{CO}_{2}$. Transfection was performed by using lipofectamine 3000 (Life Technologies) following the manufacturer's recommended protocol. A total of 200-500 ng DNA was used for each well of a 24-well plate. $200 \mathrm{nM}$ rapamycin or AP1903 (Sigma-Aldrich) was applied to the cells. The culture media were replaced every $24 \mathrm{~h}$ with fresh media containing $200 \mathrm{nM}$ rapamycin or AP1903.

\subsection{5hmC immunofluorescence staining and imaging}

HeLa cells $\left(4 \times 10^{5}\right)$ were plated on sterile coverslips in 24-well plates. After 2448 hours of rapamycin treatment, cells were fixed with $4 \%$ paraformaldehyde in PBS for 15 min and permeabilized with $0.2 \%$ Triton X-100 in PBS for 30 min at room temperature. Next, DNAs were denatured with $3 \mathrm{~N} \mathrm{HCl}$ at room temperature for $15 \mathrm{~min}$ and neutralized with $100 \mathrm{mM}$ Tris-HCl buffer (pH 8.0) for $10 \mathrm{~min}$. After extensive washing with PBS, cells were blocked with $1 \%$ BSA for $30 \mathrm{~min}$, and then incubated with rabbit anti-5-hmC polyclonal antibody (diluted at 1:500, Active Motif) for 2 hours at room temperature. After washing with PBS (3 times; 15 min each), FITC-conjugated anti-rabbit IgG (SigmaAldrich) was added to the cells and incubated for 1 hour. After thoroughly washing with 
PBS, $250 \mathrm{ng} / \mathrm{ml}$ of 4',6-diamidino-2-phenylindole (DAPI) was added to the fixed cells and then mounted the slides for confocal imaging. The fluorescent images were acquired by using a Nikon A1R+ confocal imaging system equipped with multiple laser sources (405/488/561/640 nm). $488 \mathrm{~nm}$ laser (green) was used to obtain 5hmC staining signals. 561-nm laser was used to detect mCherry for protein localization. The NISElements software was used for image analysis. The averaged FITC intensity in the nuclei of mCherry-positive cells were collected and analyzed. The data was plotted using the Prism 5 software. Images in Figure S1c were acquired using the automated high-content confocal imaging system (IN CELL Analyzer, GE Healthcare).

\subsection{Flow cytometry}

Cells were re-suspended in FACS buffer (PBS with 1\% BSA, 2 mM EDTA) and incubated with Fc blocker for 10 min on ice. After washing with FACS buffer, cells were fixed and permeabilized using the Cell Fixation/permeabilization kit from BD Biosciences. DNA were denatured by $2 \mathrm{~N} \mathrm{HCl}$ and neutralized by $10 \mathrm{mM}$ Tris- $\mathrm{HCl}(\mathrm{pH}$ 8.0) for 20 min. Next, anti-5hmC antibody (Active Motif, 1:200) and FITC conjugated goat anti-rabbit secondary antibody (at a dilution of 1:200; Thermo Fisher Scientific) were used for $5 \mathrm{hmC}$ staining. Flow cytometry analysis was performed using LSRII (BD Biosciences) and data were analyzed by using the FlowJo software.

\subsection{A dot-blot assay to quantify genomic $5 \mathrm{hmC}$ and $5 \mathrm{mC}$}

Purified genomic DNA was denatured in $0.4 \mathrm{M} \mathrm{NaOH}, 10 \mathrm{mM}$ EDTA at $95^{\circ} \mathrm{C}$ for 10 min, followed by neutralization with ice-cold $2 \mathrm{M}$ ammonium acetate ( $\mathrm{pH}$ 7.0). Twofold serial dilutions of the denatured DNA samples were spotted on a nitrocellulose 
membrane in an assembled Bio-Dot apparatus (Bio-Rad) according to the manufacturer's instructions. A synthetic oligonucleotide with a known amount of $5 \mathrm{hmC}$ was used as standard. The membrane was washed with 2 xSSC buffer, air-dried and vacuum-baked at $80^{\circ} \mathrm{C}$ for $2 \mathrm{~h}$. The dried membrane was blocked with 5\% non-fat milk for 1 hour and incubated with an anti-5hmC antibody (1:5000, Active Motif) for 1 hour at $4^{\circ} \mathrm{C}$, followed by incubation with horseradish peroxidase-conjugated anti-rabbit IgG secondary antibody (1:10,000; Sigma). The membrane was visualized by West-Q Pico Dura ECL Solution (GenDEPOT). To ensure equal loading of total DNA on the membrane, the same blot was stained with $0.02 \%$ methylene blue in $0.3 \mathrm{M}$ sodium acetate ( $\mathrm{pH}$ 5.2) to visualize the total amounts of loaded DNA samples.

\subsection{Western blotting}

Cells were lysed with RIPA buffer (150 mM NaCl, $50 \mathrm{mM}$ Tris-HCl, $\mathrm{pH}$ 8.0, 1\% Triton X-100, $0.5 \%$ sodium deoxycholate and $0.1 \%$ SDS) supplemented with protease inhibitor cocktail (GenDEPOT), and incubated on ice for $20 \mathrm{~min}$. Cell debris was removed by centrifuging at $30,000 \mathrm{x}$ g for $10 \mathrm{~min}$ at $4^{\circ} \mathrm{C}$. The protein concentration was measured by a Pierce BCA protein assay kit (Thermo Fisher Scientific). Samples were mixed with SDS sample buffer at $95^{\circ} \mathrm{C}$ for $10 \mathrm{~min}$. Whole cell lysates were resolved on $10 \%$ or 4$12 \%$ gradient SDS-PAGE and transferred onto nitrocellulose membranes. Proteins were detected by immunoblotting in TBST $(150 \mathrm{mM} \mathrm{NaCl}, 10 \mathrm{mM}$ Tris-Cl, $\mathrm{pH}$ 8.0, 0.5\% Tween-20) containing 5\% low-fat milk followed by incubation with anti-Myc (GeneTex, 1:10,000), anti-mCherry (GeneTex , 1:3,000) or anti-GAPDH (Sigma, 1:10,000) at RT for $1 \mathrm{hr}$. Then the membrane was incubated with HRP-conjugated secondary antibodies (goat 
anti-mouse IgG HRP, Sigma) and proteins were detected by using the West-Q Pico Dura ECL kit (GenDEPOT).

\subsection{Pull-down experiments and functional reconstitution in vitro}

Myc-CiDER-mCherry encoding the split CiDER (N-terminal half tagged with Myc and C-half fused with mCherry) was transfected into HEK293T cells by using Lipofectamine 3000 (Life Technologies). 48 h post-transfection, 1 X10 ${ }^{7}$ cells were lysed in a RIPA lysis buffer $(150 \mathrm{mM} \mathrm{NaCl}, 50 \mathrm{mM}$ Tris-HCl, $\mathrm{pH}$ 8.0, 1\% Triton X-100, 0.1\% sodium deoxycholate and $0.05 \%$ SDS) supplemented with protease inhibitor cocktail (GenDEPOT) and incubated on ice for 20 min. Cell debris was removed by centrifuging at $18,000 \mathrm{x} g$ for $10 \mathrm{~min}$ at $4^{\circ} \mathrm{C}$. Cell lysates were incubated with anti-Myc antibody (ab1253, Abcam) and/or a rabbit polyclonal anti-mCherry antibody (ab167453, Abcam) for 4 hours at $4^{\circ} \mathrm{C}$ followed by incubation with precleared protein $\mathrm{A} / \mathrm{G}$ beads $(30 \mathrm{ul})$ overnight at $4^{\circ} \mathrm{C}$. Protein/beads mixtures were washed with $50 \mathrm{mM}$ HEPES (pH 8.0) containing $50 \mathrm{mM} \mathrm{NaCl}$ for 5 times. Then we mixed the immunoprecipitated TET2CD, N-half or both CiDER fragments with substrate (a double-stranded 5mC containing DNA oligos as we used in an earlier study) in a reaction buffer (50 mM HEPES ( $\mathrm{pH} 8.0), 50 \mathrm{mM}$ $\mathrm{NaCl}, 1 \mathrm{mM} \alpha$-ketoglutarate, $3.7 \mu \mathrm{M}$ ammonium iron (II) sulfate hexahydrate, $0.1 \mathrm{mg} \mathrm{ml}$ $1 \mathrm{BSA}, 1 \mathrm{mM} \mathrm{ATP})$ at $37^{\circ} \mathrm{C}$ for $30 \mathrm{~min}$. EDTA $(11 \mathrm{mM})$ was then added to quench the reaction. DNA and protein mixtures were eluted with $50 \mathrm{mM}$ HEPES ( $\mathrm{pH}$ 8.0) containing $200 \mathrm{mM} \mathrm{NaCl}, 0.2 \% \mathrm{SDS}$ with incubation at $95^{\circ} \mathrm{C}$ for $10 \mathrm{~min}$. DNA fragments were further purified by MicroElute Cycle-Pure Kit (Omega). 5hmC level was measured by the dot-blot assay as described above. 


\section{CONCLUSION}

In summary, we engineered split-TET2CD fragments based on the TET2CD/5hmC crystal structure to restrict its function temporarily, then employed the rapamycin triggered protein dimerization widget to restore the catalytic function of TET2CD to convert $5 \mathrm{mC}$ to $5 \mathrm{hmC}$. Together, it is CiDER that offers a temporal and reversible control of $5 \mathrm{hmC}$ level in mammalian cells. 


\section{REFERENCES}

1. Li, E.; Zhang, Y., DNA methylation in mammals. Cold Spring Harb Perspect Biol 2014, 6 (5), a019133.

2. He, Y. F.; Li, B. Z.; Li, Z.; Liu, P.; Wang, Y.; Tang, Q.; Ding, J.; Jia, Y.; Chen, Z.; Li, L.; Sun, Y.; Li, X.; Dai, Q.; Song, C. X.; Zhang, K.; He, C.; Xu, G. L., Tet-mediated formation of 5-carboxylcytosine and its excision by TDG in mammalian DNA. Science 2011, 333 (6047), 1303-7.

3. Ito, S.; Shen, L.; Dai, Q.; Wu, S. C.; Collins, L. B.; Swenberg, J. A.; He, C.; Zhang, Y., Tet proteins can convert 5-methylcytosine to 5-formylcytosine and 5-carboxylcytosine. Science 2011, 333 (6047), 1300-3.

4. Tahiliani, M.; Koh, K. P.; Shen, Y.; Pastor, W. A.; Bandukwala, H.; Brudno, Y.; Agarwal, S.; Iyer, L. M.; Liu, D. R.; Aravind, L.; Rao, A., Conversion of 5-methylcytosine to 5hydroxymethylcytosine in mammalian DNA by MLL partner TET1. Science 2009, 324 (5929), 930-5.

5. Spruijt, C. G.; Gnerlich, F.; Smits, A. H.; Pfaffeneder, T.; Jansen, P. W.; Bauer, C.; Munzel, M.; Wagner, M.; Muller, M.; Khan, F.; Eberl, H. C.; Mensinga, A.; Brinkman, A. B.; Lephikov, K.; Muller, U.; Walter, J.; Boelens, R.; van Ingen, H.; Leonhardt, H.; Carell, T.; Vermeulen, M., Dynamic readers for 5-(hydroxy)methylcytosine and its oxidized derivatives. Cell 2013, 152 (5), 1146-59.

6. Lio, C. W.; Zhang, J.; Gonzalez-Avalos, E.; Hogan, P. G.; Chang, X.; Rao, A., Tet2 and Tet3 cooperate with B-lineage transcription factors to regulate DNA modification and chromatin accessibility. Elife 2016, 5. 
7. Kellinger, M. W.; Song, C. X.; Chong, J.; Lu, X. Y.; He, C.; Wang, D., 5-formylcytosine and 5-carboxylcytosine reduce the rate and substrate specificity of RNA polymerase II transcription. Nat Struct Mol Biol 2012, 19 (8), 831-3.

8. Su, M.; Kirchner, A.; Stazzoni, S.; Muller, M.; Wagner, M.; Schroder, A.; Carell, T., 5Formylcytosine Could Be a Semipermanent Base in Specific Genome Sites. Angew Chem Int Ed Engl 2016, 55 (39), 11797-800.

9. Ko, M.; Huang, Y.; Jankowska, A. M.; Pape, U. J.; Tahiliani, M.; Bandukwala, H. S.; An, J.; Lamperti, E. D.; Koh, K. P.; Ganetzky, R.; Liu, X. S.; Aravind, L.; Agarwal, S.; Maciejewski, J. P.; Rao, A., Impaired hydroxylation of 5-methylcytosine in myeloid cancers with mutant TET2. Nature 2010, 468 (7325), 839-43.

10. Huang, Y.; Rao, A., Connections between TET proteins and aberrant DNA modification in cancer. Trends Genet 2014, 30 (10), 464-74.

11. Lu, X.; Zhao, B. S.; He, C., TET family proteins: oxidation activity, interacting molecules, and functions in diseases. Chem Rev 2015, 115 (6), 2225-39.

12. Delhommeau, F.; Dupont, S.; Della Valle, V.; James, C.; Trannoy, S.; Masse, A.; Kosmider, O.; Le Couedic, J. P.; Robert, F.; Alberdi, A.; Lecluse, Y.; Plo, I.; Dreyfus, F. J.; Marzac, C.; Casadevall, N.; Lacombe, C.; Romana, S. P.; Dessen, P.; Soulier, J.; Viguie, F.; Fontenay, M.; Vainchenker, W.; Bernard, O. A., Mutation in TET2 in myeloid cancers. N Engl J Med 2009, 360 (22), 2289-301.

13. Langemeijer, S. M.; Kuiper, R. P.; Berends, M.; Knops, R.; Aslanyan, M. G.; Massop, M.; Stevens-Linders, E.; van Hoogen, P.; van Kessel, A. G.; Raymakers, R. A.; Kamping, E. J.; Verhoef, G. E.; Verburgh, E.; Hagemeijer, A.; Vandenberghe, P.; de Witte, T.; van der 
Reijden, B. A.; Jansen, J. H., Acquired mutations in TET2 are common in myelodysplastic syndromes. Nat Genet 2009, 41 (7), 838-42.

14. Hashimoto, H.; Pais, J. E.; Zhang, X.; Saleh, L.; Fu, Z. Q.; Dai, N.; Correa, I. R., Jr.; Zheng, Y.; Cheng, X., Structure of a Naegleria Tet-like dioxygenase in complex with 5methylcytosine DNA. Nature 2014, 506 (7488), 391-5.

15. Hu, L.; Li, Z.; Cheng, J.; Rao, Q.; Gong, W.; Liu, M.; Shi, Y. G.; Zhu, J.; Wang, P.; Xu, Y., Crystal structure of TET2-DNA complex: insight into TET-mediated 5mC oxidation. Cell 2013, 155 (7), 1545-55.

16. Banaszynski, L. A.; Liu, C. W.; Wandless, T. J., Characterization of the FKBP.rapamycin.FRB ternary complex. J Am Chem Soc 2005, 127 (13), 4715-21.

17. Clackson, T.; Yang, W.; Rozamus, L. W.; Hatada, M.; Amara, J. F.; Rollins, C. T.; Stevenson, L. F.; Magari, S. R.; Wood, S. A.; Courage, N. L.; Lu, X.; Cerasoli, F., Jr.; Gilman, M.; Holt, D. A., Redesigning an FKBP-ligand interface to generate chemical dimerizers with novel specificity. Proc Natl Acad Sci U S A 1998, 95 (18), 10437-42.

18. Ibrahimi, A.; Vande Velde, G.; Reumers, V.; Toelen, J.; Thiry, I.; Vandeputte, C.; Vets, S.; Deroose, C.; Bormans, G.; Baekelandt, V.; Debyser, Z.; Gijsbers, R., Highly efficient multicistronic lentiviral vectors with peptide 2A sequences. Hum Gene Ther 2009, 20 (8), $845-60$.

19. Kim, J. H.; Lee, S. R.; Li, L. H.; Park, H. J.; Park, J. H.; Lee, K. Y.; Kim, M. K.; Shin, B. A.; Choi, S. Y., High cleavage efficiency of a $2 \mathrm{~A}$ peptide derived from porcine teschovirus-1 in human cell lines, zebrafish and mice. PLoS One 2011, 6 (4), e18556. 


\section{APPENDIX}

\section{Figure A1:}

CiDER: Myc-NLS-T2SN-linker-FRB-T2A-FKBP12-linker-T2Sc-linker-mCherry (797 residues without mCherry tag; 1047 residues total)

MEQKLISEEDLKRPAATKKAGQAKKKKGGSASGGSDFPSCRCVEQI IEKDEGPFYTHLG AGPNVAAIREIMEERFGQKGKAIRIERVIYTGKEGKSSQGCPIAKWVVRRSSSEEKLLC LVRERAGHTCEAAVIVILILVWEGIPLSLADKLYSELTETLRKYGTLTNRRCALNEERT CACQGLDPETCGASFSFGCSWSMYYNGCKFARSKI PRKFKLLGDDPKEEEKLESHLQNL STLMAPTYKKLAPDAYNNQIEYEHRAPECRLGLKEGRPFSGVTACLDFCAHAHRDLHNM QGAPGGGGSGGGGSGGGGS ILWHEMWHEGLEEASRLYFGERNVKGMFEVLEPLHAMMER GPQTLKETSFNQAYGRDLMEAQEWCRKYMKSGNVKDLTQAWDLYYHVFRRISKGSGEGR GSLITCGDVEENPGPMGVQVETISPGDGRTFPKRGQTCVVHYTGMLEDGKKFDSSRDRN KPFKFMLGKQEVIRGWEEGVAQMSVGQRAKLTISPDYAYGATGHPGI IPPHATLVFDVE LLKLEGSGSGSGSGSGSPGNGSTLVCTLTREDNREFGGKPEDEQLHVLPLYKVSDVDEF GSVEAQEEKKRSGAIQVLSSFRRKVRMLAEPVKPGKKLLPGLGAEDNDEVWSDSEQSFL DPDIGGVAVAPTHGSILIECAKRELHATTPLKNPNRNHPTRISLVFYQHKSMNEPKHGL ALWEAKMAEKAREKEEECEKYGPDYVPQKSHGKKVKREPAEPHETSEPTYLRFIKSLAE RTMSVTTDSTVTTSPYAFTRVTGPYNRYIGTGSGSGSGSGSGSMVSKGEEDNMAIIKEF MRFKVHMEGSVNGHEFEIEGEGEGRPYEGTQTAKLKVTKGGPLPFAWDILSPQFMYGSK AYVKHPADIPDYLKLSFPEGFKWERVMNFEDGGVVTVTQDSSLQDGEFIYKVKLRGTNF 
PSDGPVMQKKTMGWEASSERMYPEDGALKGEIKQRLKLKDGGHYDAEVKTTYKAKKPVQ LPGAYNVNIKLDITSHNEDYTIVEQY

ERAEGRHSTGGMDELYK*

\title{
Annotation:
}

c-myc tag

NLS

FRB

\section{T2A: self-cleaving 2A peptide}

FKBP1A

mCherry

T2S: engineered minimal TET2 C+D domain composed of two components $\left(T_{2} \mathrm{~S}_{\mathrm{N}}, 1129-1430 ; \mathrm{T}_{\mathrm{C}}, 1431-2002 / \Delta 1463-1838\right)$

\begin{abstract}
ATGGAACAAAAACTTATTTCTGAAGAAGATCTGAAAAGGCCGGCGGCCACGAAAAAGGC CGGCCAGGCAAAAAAGAAAAAGGGAGGTTCCGCTAGCGGAGGTTCGGATTTCCCATCT TGCAGATGTGTAGAGCAAATTATTGAAAAAGATGAAGGTCCTTTTTATACCCATCTAGG AGCAGGTCCTAATGTGGCAGCTATTAGAGAAATCATGGAAGAAAGGTTTGGACAGAAGG GTAAAGCTATTAGGATTGAAAGAGTCATCTATACTGGTAAAGAAGGCAAAAGTTCTCAG GGATGTCCTATTGCTAAGTGGGTGGTTCGCAGAAGCAGCAGTGAAGAGAAGCTACTGTG TTTGGTGCGGGAGCGAGCTGGCCACACCTGTGAGGCTGCAGTGATTGTGATTCTCATCC
\end{abstract}


TGGTGTGGGAAGGAATCCCGCTGTCTCTGGCTGACAAACTCTACTCGGAGCTTACCGAG ACGCTGAGGAAATACGGCACGCTCACCAATCGCCGGTGTGCCTTGAATGAAGAGAGAAC TTGCGCCTGTCAGGGGCTGGATCCAGAAACCTGTGGTGCCTCCTTCTCTTTTGGTTGTT CATGGAGCATGTACTACAATGGATGTAAGTTTGCCAGAAGCAAGATCCCAAGGAAGTTT AAGCTGCTTGGGGATGACCCAAAAGAGGAAGAGAAACTGGAGTCTCATTTGCAAAACCT GTCCACTCTTATGGCACCAACATATAAGAAACTTGCACCTGATGCATATAATAATCAGA TTGAATATGAACACAGAGCACCAGAGTGCCGTCTGGGTCTGAAGGAAGGCCGTCCATTC TCAGGGGTCACTGCATGTTTGGACTTCTGTGCTCATGCCCACAGAGACTTGCACAACAT GCAGGGCGCGC GGAGGTGGTGGCAGCGGTGGAGGAGGTTCTGGGGGCGGTGGCTCAA TTTTATGGCATGAGATGTGGCATGAGGGTTTGGAAGAGGCATCTAGATTGTATTTCGGT GAAAGAAATGTCAAGGGAATGTTCGAAGTTTTAGAACCGTTGCACGCTATGATGGAGAG AGGTCCACAGACTCTAAAGGAGACTTCCTTCAACCAAGCTTATGGAAGGGACCTAATGG AGGCTCAAGAATGGTGTAGAAAATACATGAAAAGTGGAAATGTAAAGGACCTTACACAA GСTTGGGATCTCTACTACCATGTTTTTAGGAGAATATCTAAAGGAAGTGGTGAGGGTAG GGGAAGTTTATTAACCTGTGGGGATGTTGAAGAAAATCCAGGTCCTATGGGCGTACAAG TTGAAACTATCAGCCCTGGGGACGGCAGAACCTTTCCGAAGAGGGGACAGACATGTGTT GTTCACTATACTGGAATGTTGGAAGATGGTAAGAAGTTCGATAGCAGCAGAGATAGGAA TAAACCATTTAAATTCATGCTTGGCAAGCAAGAAGTGATTAGGGGTTGGGAAGAAGGTG TCGCTCAAATGAGTGTAGGTCAGAGGGCTAAGTTAACAATTAGTCCTGATTATGCTTAT GGCGCTACAGGTCATCCAGGAATCATTCCCCCACATGCTACTCTTGTTTTCGACGTTGA ATTGCTCAAGCTTGAAGGATCAGGTTCTGGATCTGGTTCAGGATCAGGCTCACCCGGGA ATGGCAGCACATTGGTATGCACTCTCACTAGAGAAGACAATCGAGAATTTGGAGGAAAA 
CCTGAGGATGAGCAGCTTCACGTTCTGCCTTTATACAAAGTCTCTGACGTGGATGAGTT TGGGAGTGTGGAAGCTCAGGAGGAGAAAAAACGGAGTGGTGCCATTCAGGTACTGAGTT СTTTTCGGCGAAAAGTCAGGATGTTAGCAGAGCCAGTCAAGCCCGGGAAGAAGCTTCTT

CCCGGGCTTGGTGCAGAGGACAACGATGAGGTCTGGTCAGACAGCGAGCAGAGCTTTCT GGATCCTGACATTGGGGGAGTGGCCGTGGCTCCAACTCATGGGTCAATTCTCATTGAGT GTGCAAAGCGTGAGCTGCATGCCACAACCCCTTTAAAGAATCCCAATAGGAATCACCCC ACCAGGATCTCCСTCGTCTTTTACCAGCATAAGAGCATGAATGAGCCAAAACATGGCTT GGCTCTTTGGGAAGCCAAAATGGCTGAAAAAGCCCGTGAGAAAGAGGAAGAGTGTGAAA AGTATGGCCCAGACTATGTGCCTCAGAAATCCCATGGCAAAAAAGTGAAACGGGAGCCT GCTGAGCCACATGAAACTTCAGAGCCCACTTACCTGCGTTTCATCAAGTCTCTTGCCGA AAGGACCATGTCCGTGACCACAGACTCCACAGTAACTACATCTCCATATGCCTTCACTC GGGTCACAGGGCCTTACAACAGATATATAGGTACCGGGTCGGGTAGTGGCTCTGGTAG TGGTTCTGGTTCTATGGTGAGCAAGGGCGAGGAGGATAACATGGCCATCATCAAGGAGT TCATGCGCTTCAAGGTGCACATGGAGGGCTCCGTGAACGGCCACGAGTTCGAGATCGAG GGCGAGGGCGAGGGCCGCCCCTACGAGGGCACCCAGACCGCCAAGCTGAAGGTGACCAA GGGTGGCCCCСTGCCCTTCGCCTGGGACATCCTGTCCССTCAGTTCATGTACGGCTCCA AGGCCTACGTGAAGCACCCCGCCGACATCCCCGACTACTTGAAGCTGTCCTTCCCCGAG GGCTTCAAGTGGGAGCGCGTGATGAACTTCGAGGACGGCGGCGTGGTGACCGTGACCCA GGACTCCTCCCTGCAGGACGGCGAGTTCATCTACAAGGTGAAGCTGCGCGGCACCAACT TCCCCTCCGACGGCCCCGTAATGCAGAAGAAGACCATGGGCTGGGAGGCCTCCTCCGAG CGGATGTACCCCGAGGACGGCGCCCTGAAGGGCGAGATCAAGCAGAGGCTGAAGCTGAA GGACGGCGGCCACTACGACGCTGAGGTCAAGACCACCTACAAGGCCAAGAAGCCCGTGC 
AGCTGCCCGGCGCCTACAACGTCAACATCAAGTTGGACATCACCTCCCACAACGAGGAC TACACCATCGTGGAACAGTACGAACGCGCCGAGGGCCGCCACTCCACCGGCGGCATGGA CGAGCTGTACAAGTAGGCGGCCGC 